\title{
A NEW METHODOLOGY ON STRATEGIC PLANNING
}

\section{Hakan Bütüner ${ }^{1}$}

\begin{abstract}
A systematic method of strategic planning is anticipated to be easily understood and straightforward; based on fundamentals; and to be universally applicable for any type of business. Accordingly, this methodology is generated for the purpose of assembling the disconnected and disorderly ideas, processes, and techniques (written on strategy and business development) under the same roof, in order to develop a systematic methodology that is easily understandable and applicable.
\end{abstract}

As many sources exhort managers to "think strategically" or prescribe "strategic leadership" to helicopter out of tactical day-to-day management, only a few address how to make this happen. Where strategic analysis tools are explained, this is most frequently done conceptually rather than practically on how to utilize the tools for strategic planning. Moreover, as fondly as it may sound, there is an exact approach or systematic thinking on this issue; our intention is to bring in a new perspective to the reader and, more significantly, to provide a different benefit by the application of this systematic methodology.

Systematic strategic planning (SSP) consists of a framework of phases through which each project passes, a pattern of procedures for straight-forward planning, and the fundamentals involved in any strategic planning project.

JEL Classification Numbers: M10, DOI: http://dx.doi.org/10.12955/cbup.v2.443

Keywords: systematic, strategy, planning, strategic planning, business plan

\section{Introduction}

Before beginning with strategic planning, businesses must have articulated their missions and visions, and identified their basic policies (see Figure 1). For this reason, proper formulation of mission, vision, and basic policies will play a determining role for the success of a strategic plan.

Mission, vision, and basic policies are elements that form the corporate identity of a business. A business cannot be identified solely by its name, logo or workflow. The know-how, experience and expertise of the business, and the corporate attitude it has developed will create a specific corporate identity. One of the functions of strategic planning is to establish a stronger link between the corporate identity of the business and the products and services it offers.

Strategic plan outlines the path between the current status of business and the desired status to achieve. It helps the business to establish its objectives, goals, as well as the decisions to achieve these objectives and goals. It involves a long-term and prospective perspective. This article is intended to briefly explain how strategic planning can be done through a systematic method.

A strategic plan provides guidance for the preparation of functional plans and business budget in such a manner that they reflect the objectives, goals, and grand strategies of the strategic plan during the implementation phase, as well as for basing resource allocation on priorities.

Functional plans help in the implementation of strategic plans by organizing and activating specific subunits of the business (marketing, finance, production, etc.) to pursue the business strategy in daily activities. Greatest responsibilities are in the implementation or execution of a strategic plan. Thus, functional plans directly address such issues as the efficiency and effectiveness of production and marketing systems, the quality and extent of customer service, and the success of particular products in increasing their market share.

Shorter time horizon is critical in implementing a business strategy for two reasons. First, it focuses functional managers' attention on what needs to be done now to make the business strategy work. Second, the shorter time horizon allows functional managers to recognize current conditions and adjust to changing conditions in developing functional plans.

\footnotetext{
${ }^{1}$ Hakan Bütüner, Industrial Management and Engineering Co., Turkey, hakan.butuner@imeco-tr.com
} 
Figure 1: Strategic planning - before and after

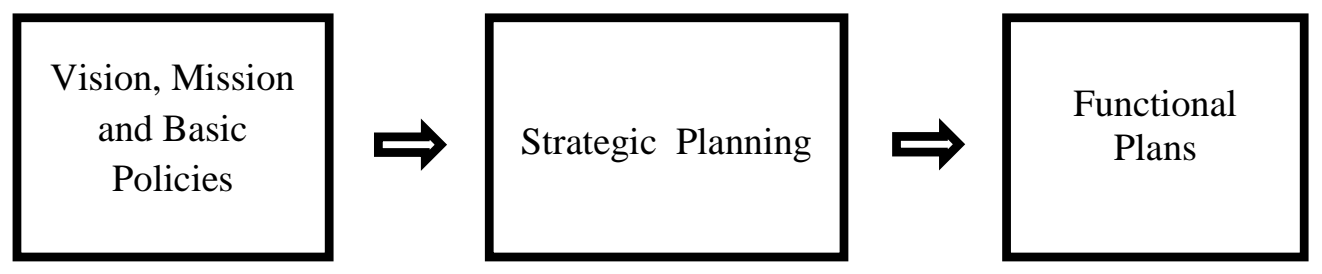

Source: Author

Functional plans are more specific than a business strategy to guide functional actions taken in key parts of the company to implement business strategy (see Figure 2). Business strategy provides general direction. Functional plans give specific guidance to managers responsible for accomplishing annual objectives to ensure that managers know how to meet annual objectives.

Specific functional plans improve the willingness of operating managers to implement strategic decisions, when those decisions represent major changes in the current strategy of the firm.

Functional plans are delegated by the business-level managers to principal subordinates charged with running the operating areas of the business. Operating managers similarly establish annual objectives and operating plans that help accomplish business objectives and strategies. The involvement of operating managers contributes to a successful implementation. Most critically, active involvement increases commitment to the strategies developed.

It is difficult to generalize about the development of plans across functional areas. Within each functional area, the importance of key variables varies across business situations.

\section{Strategic Planning}

In summary, strategic planning helps a business answer the following four basic questions:

- Where are we?

- Where do we want to go?

- How can we reach our target destination?

- How can we monitor and evaluate our success?

Answers to the above questions make up the strategic planning process. The answer to the question "where are we?" enables a status analysis involving a comprehensive review and evaluation of the internal and external environment, in which the business operates.

The answer to the question "what do we want to achieve?" lays down: the strategic objectives, which represent the conceptual results towards which efforts and actions will be designed, as well as the goals, which represent measurable results required to be achieved so that the objectives can be attained, in the light of the mission, which is a brief expression of the reason for being of the business; the vision, which is a conceptual, realistic, and brief expression of the desired future; and the basic principles that guide the operations of the business.

The main strategies, which are the decisions to be used to achieve strategic objectives and goals, answer the question "How can we reach our target destination?"

Finally, compilation of management information, monitoring for reporting of implementation plan, the evaluation of the extent to which the results achieved are consistent with the previously established mission, vision, basic policies, objectives and goals (i.e. performance evaluation) and the assessment 
process implying the review of the plan in the light of the results answer the question "How can we monitor and evaluate our success?"

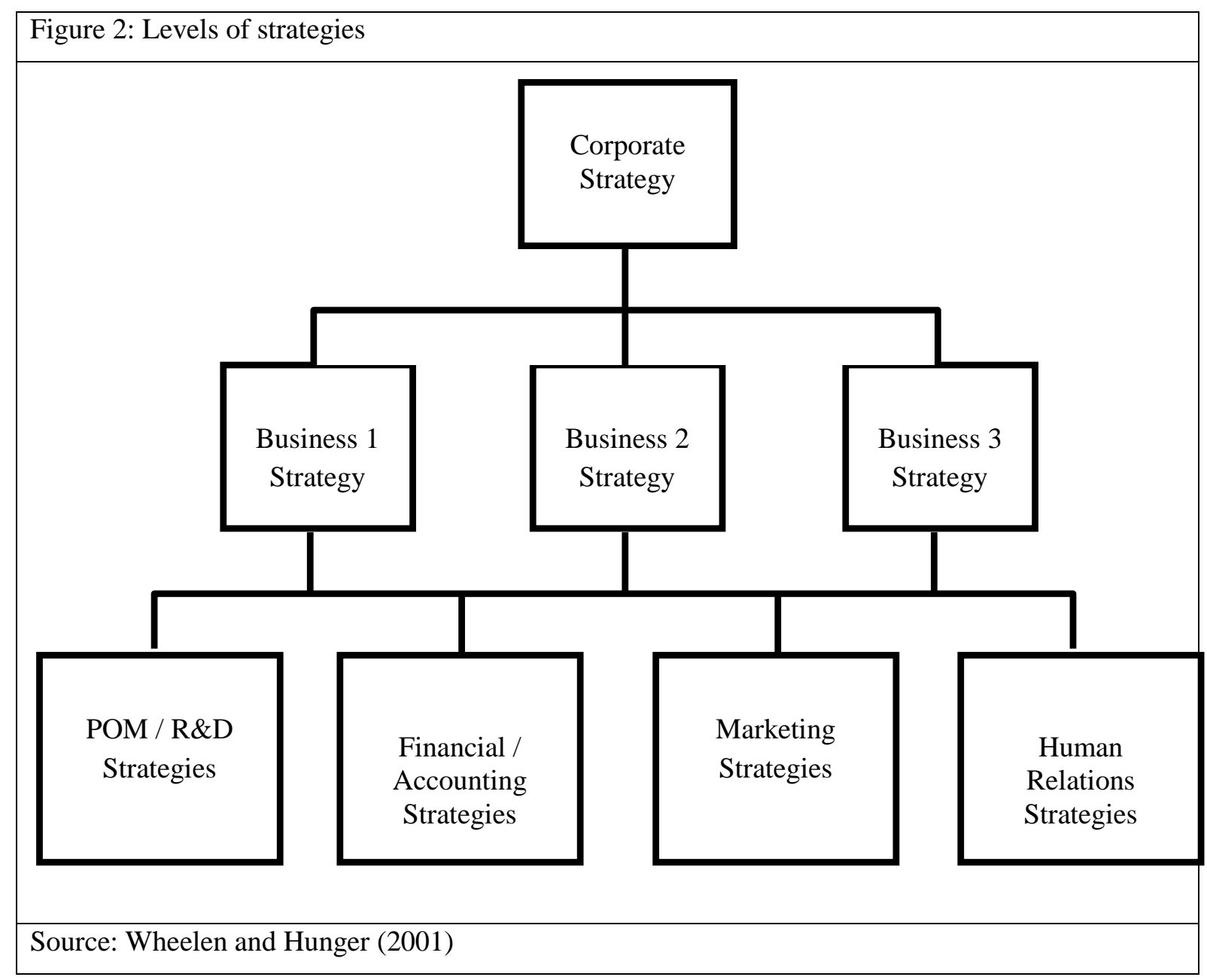

\section{Systematic Strategic Planning (SSP)}

Systematic Strategic Planning or SSP is the pattern of procedures (see Figure 3) by which an organization defines its current status, opportunities, long-term goals, and the strategies for which to achieve them.

The aims of SSP are: to force a look into the future, and, therefore, provides an opportunity to influence the future, or assume a proactive posture; to provide better awareness of needs and environment; to help define and focus on the objectives of the organization; to provide a sense of direction, continuity, and effective leadership; and to plug everyone into the system and provides standards of accountability for people, programs, and allocated resources.

The techniques to be used for strategic planning should not be perceived as a systematic procedure, and should be continuously repeatable and modifiable, depending on the characteristics of individual cases. Certain working forms (in the forms of key documents and output) are used in appying the techniques in each section or steps of the SSP pattern.

Systematic strategic planning - full version consists of a framework of phases through which each project passes, a pattern of sections for straight-forward planning, and the fundamentals involved in any strategic planning project.

\section{Systematic Strategic Planning-Phases}

Each strategic planning project has four phases. These are: 


\section{Orientation}

2. Overall (corporate) strategic plan

3. Detailed (business) strategic plans

4. Implementation plan and control

In Phases II and III, the planning specialist follows a method of procedures to achieve alternative strategic plans.

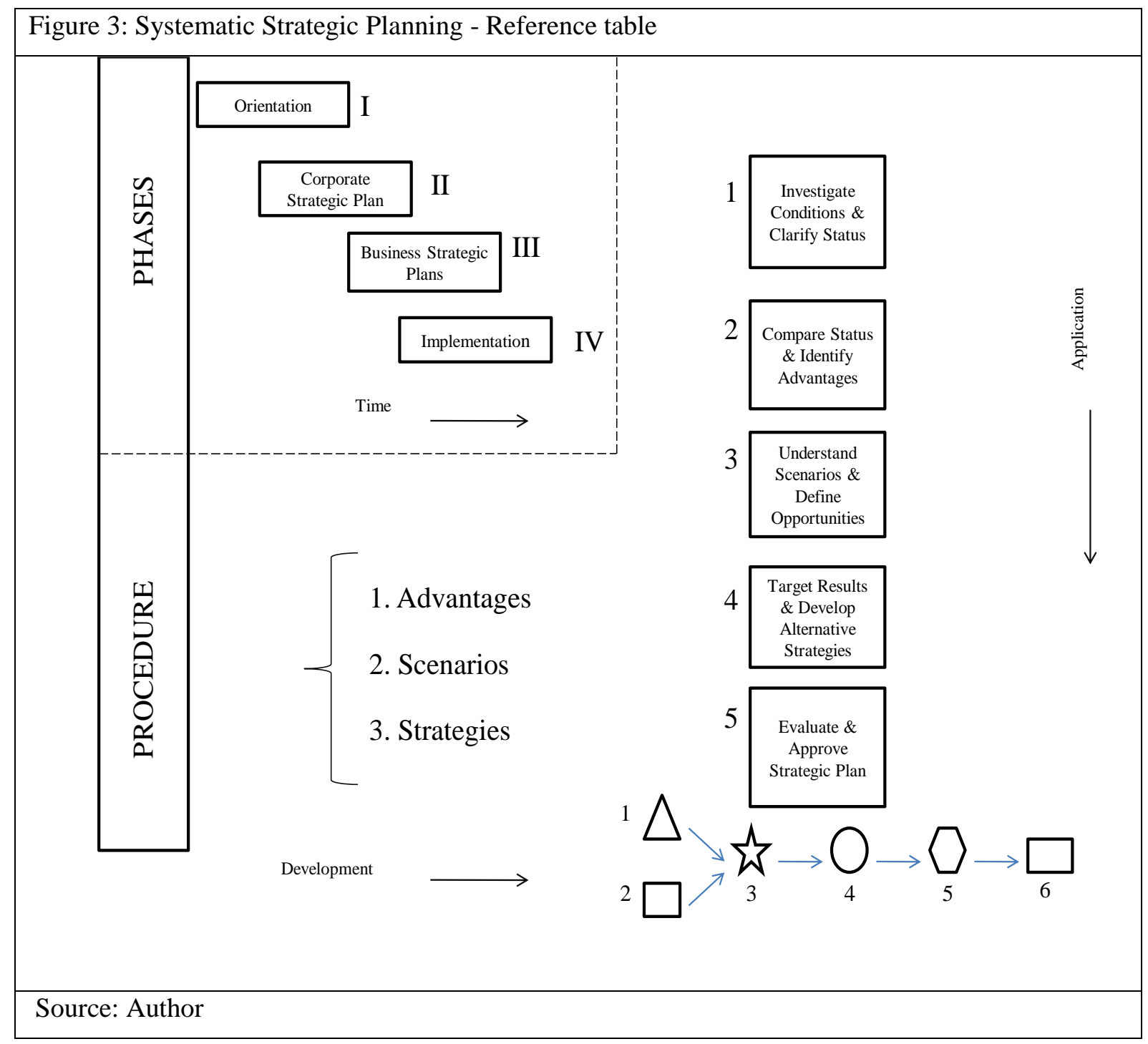

In holdings or large businesses, planning specialist uses Phase II in full SSP version to develop overall strategic plan. Planning specialist may repeat Phase III of the full version to develop detailed strategic plans of each business or division of the holding or large business, or may use shortened SSP version instead if the business is small.

\section{Orientation}

In this phase, understanding the objective(s) of the assignment-its purpose, goals, priorities, or requirements takes place. The external conditions are determined-basic assumptions or other surrounding legal, financial, technological, political, organizational, or economical constraints are to be considered. The planning situation is clarifying - who is responsible for doing what by when, where to work, others involved, and any mandatory aspects of the assignment or any constraints under which the planning is to be done. The scope is determining the extents or boundaries of the planning. 
Furthermore, questions to encourage creative thinking about the organization under review are prepared. For example, these questions may be intended to identify the changes in the expectations and priorities of clients to draw a picture of the future of the organization, the competitive environment, and domestic and international trends in the industry. It is important that the questions are prepared in such a manner that a Brainstorming environment will be created to the extent possible.

Particular attention must be paid to ensure that a comfortable and informal working environment, freed from day-to-day procedures, is created. In order to objectively collect the information about the organization under review, experienced individuals outside the organization, but from amongst stakeholders (e.g. suppliers, clients, vendors, etc.), are identified. In addition, relevant knowledgeable and participating individuals are identified from the organization (regardless of hierarchy).

\section{Overall (Corporate) Strategic Plan}

Here, "corporate" represents a group of businesses or a large business consisting of various divisions. For example, for a group of businesses active in various industries, a comprehensive and overall strategic plan must be handled in this phase.

Corporate strategic plan is a document that provides guidance for the employees, and information for stakeholders through its high level statement of how the organization proposes to go about its work over the next three to five years. The method forming the sections required for Phase II is explained briefly in the following sections.

\section{Detailed (Business) Strategic Plans}

It is the phase in which separate strategic plans are prepared for each business or division. It ensures that strategic plans at the level of businesses are aligned and integrated with overall strategic plan.

The sections are applied once during Phase II, to develop the overall strategic plan. Then, the sections are repeated in Phase III for each business or division.

\section{Implementation Plan and Control}

The implementation plan is a tool that gets corporate and businesses strategic plans underway. It is a set of activities designed to achieve the objectives of the project. Implementation plan is about how organization reaches objectives that are determined in strategic plans. In the implementation plan, organizations decide that where, how, when and to whom actions are done.

The business has to make prioritization during this implementation phase. After describing the goals prioritized, assigned to responsible units, the activities and projects required to achieve these goals will be explained here in order of priority.

This phase also involves the preparation of budgets for utilization of resources required for realization of action plans (see Figure 4). After expressing each goal in the activities, these activities must be linked to the budget. The main purpose here is to be able to measure the cost of each activity, by laying down the resource and cost structure during the budget preparation process, as well as to assist the process of prioritizing expenditures.

Furthermore, performance criteria are monitored in this phase, to identify deviations from goals and analyze the reasons of these deviations.

Monitoring is the regular follow-up and reporting of the progress towards goals specified in the strategic plan. Evaluation is the measurement of implementation results against strategic objective and goals and analysis of the consistency and relevance of these objective and goals. Performance measurement is the measurement of implementation results using performance indicators. 


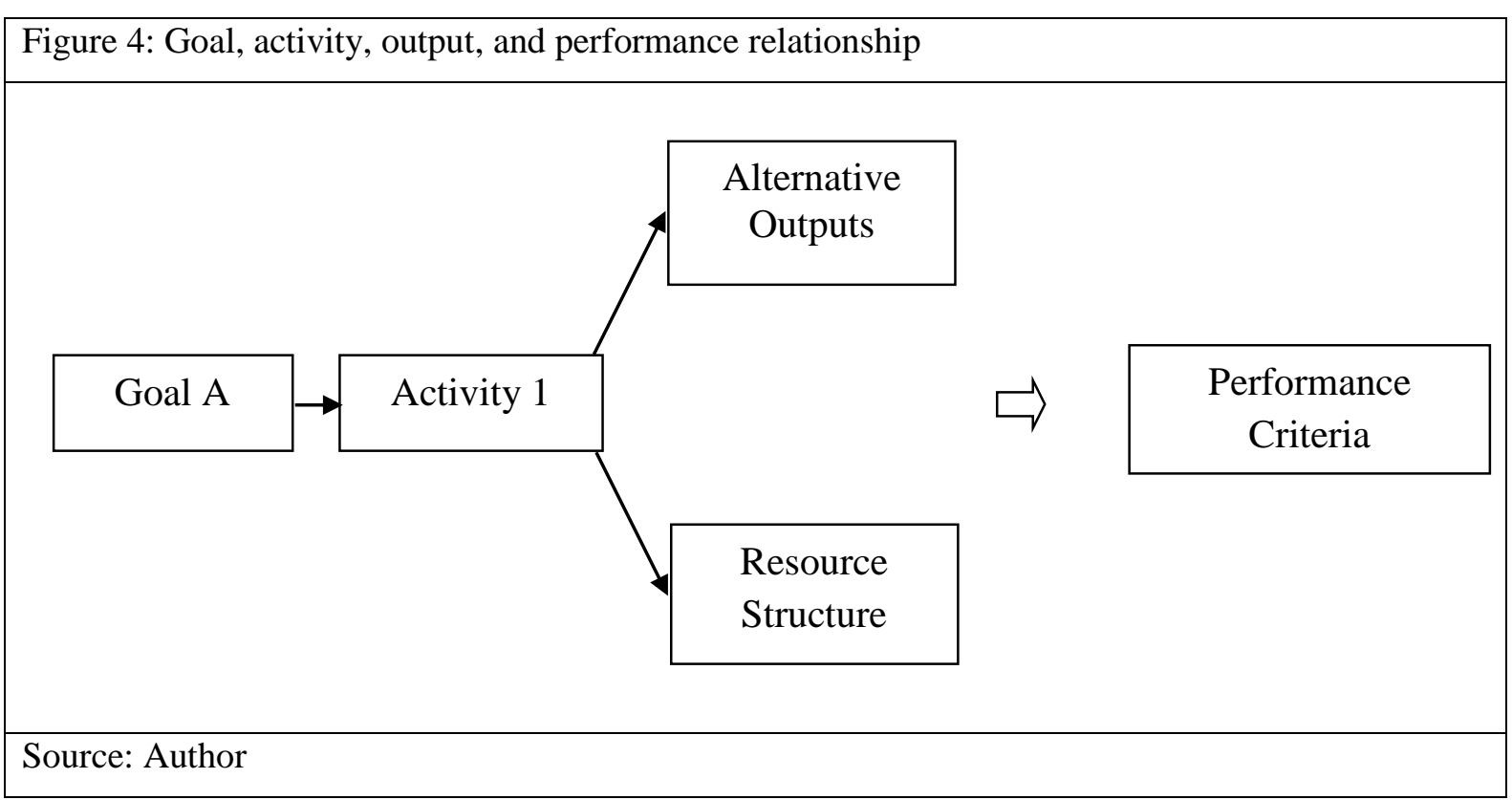

A performance indicator is expressed in terms of time, quantity, quality, and cost in order to ensure its measurability. Performance indicators are categorized as input, output, productivity, result, and quality.

Deviations from goals must be identified by following up the performance indicators and the reasons of these deviations must be analyzed. If changes are observed, in terms of the above considerations, unexpected or undesired results are coming about or existing strategic objectives and goals are not realistic, then the plan is revised, re-evaluated, and is continued to be implemented with its updated version.

Basic questions in monitoring and evaluation are:

- What did we do?

- How do we understand that we have achieved?

- How effective is implementation?

- What should be changed?

\section{Systematic Strategic Planning-Three Fundamentals}

The Fundamentals of strategic planning, the basis on which any strategic planning must rest, are Competitive Advantages, Scenarios, and Strategies.

\section{Competitive Advantages}

"Competitive Advantages" is fundamental A. As a result of investigating internal and external factors, weaknesses and strengths of the organization are determined. Based on the comparison of the strengths with market conditions, the unique strengths (i.e. competitive advantages of the organization) are determined.

\section{Scenarios}

"Scenarios" is fundamental B. Scenario analysis is made on external factors-macroeconomic analysis, industry analysis, etc. By this analysis, negative and positive scenarios are determined. These scenarios help to predict the industry's future. 


\section{Strategies}

"Strategies" is fundamental C. It is the fundamental that helps the organization to define how to reach the opportunity, which is brought out by matching fundamental A, i.e. competitive advantage, with fundamental B, i.e. scenarios. This fundamental characterizes the process that organization should follow in order to to reach the opportunity, and guides the organization about how it should be done.

\section{Systematic Strategic Planning-Sections}

It consists of a pattern of five sections for straightforward planning to determine the three fundamentals involved in any strategic planning project (see Figure 5).

\section{Investigating Environmental and Internal Conditions-Clarification of Current Status}

Since, the first section of SSP is to answer the question "where are we?" this requires a comprehensive status analysis. Status analysis essentially covers the following assessments:

- Analysis of the internal structure of the organization-the duties and authorities, performances, problems, potentials, institutional culture, human resources, technology level, etc.

- Environmental analysis - analysis of external conditions as well as the environment, in which the organization operates and related parties (target group of the organization and parties affected negatively or positively from the organization's activities).

- Analysis of developments, which the organization may face and affected from in the future.

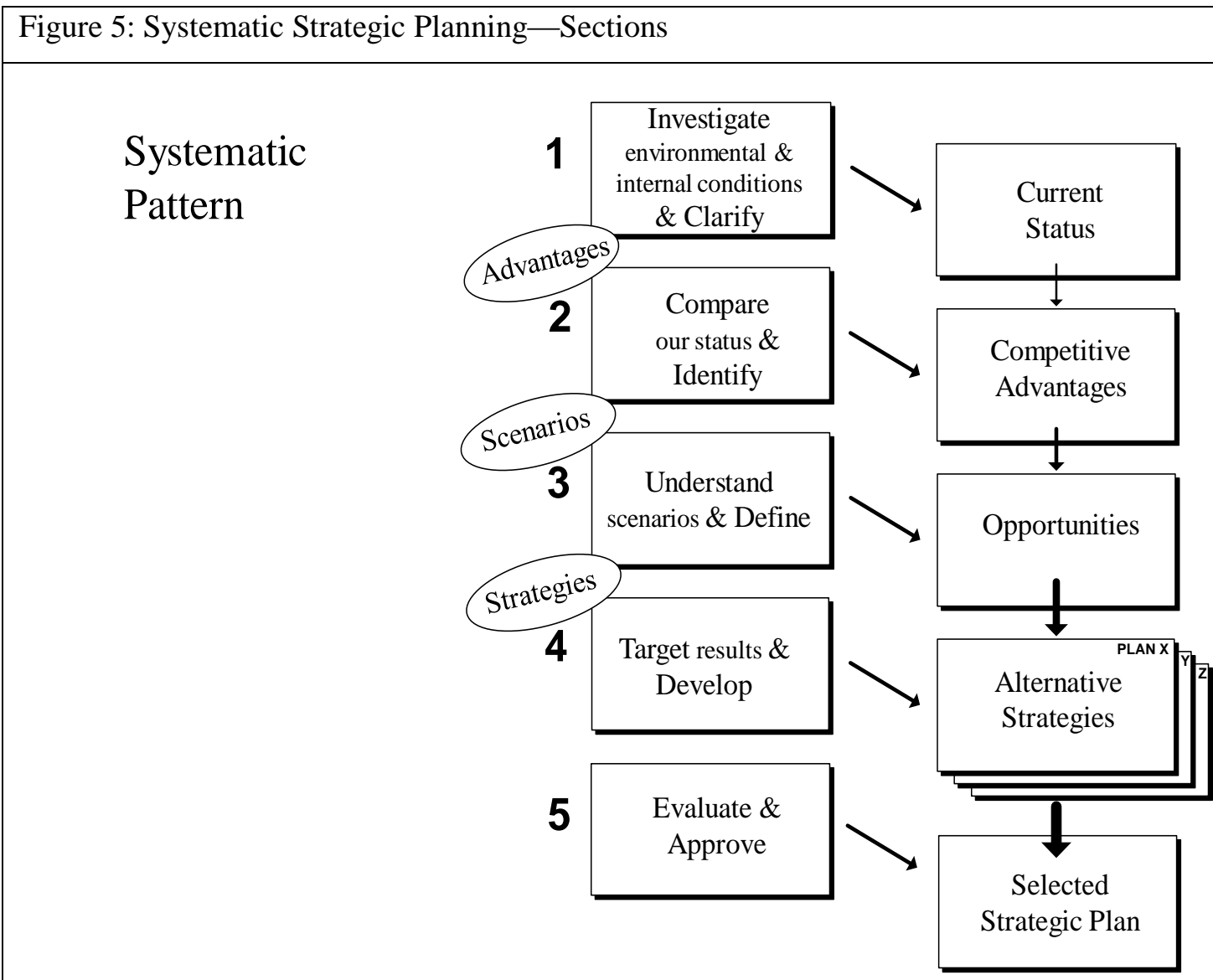

Source: Author 


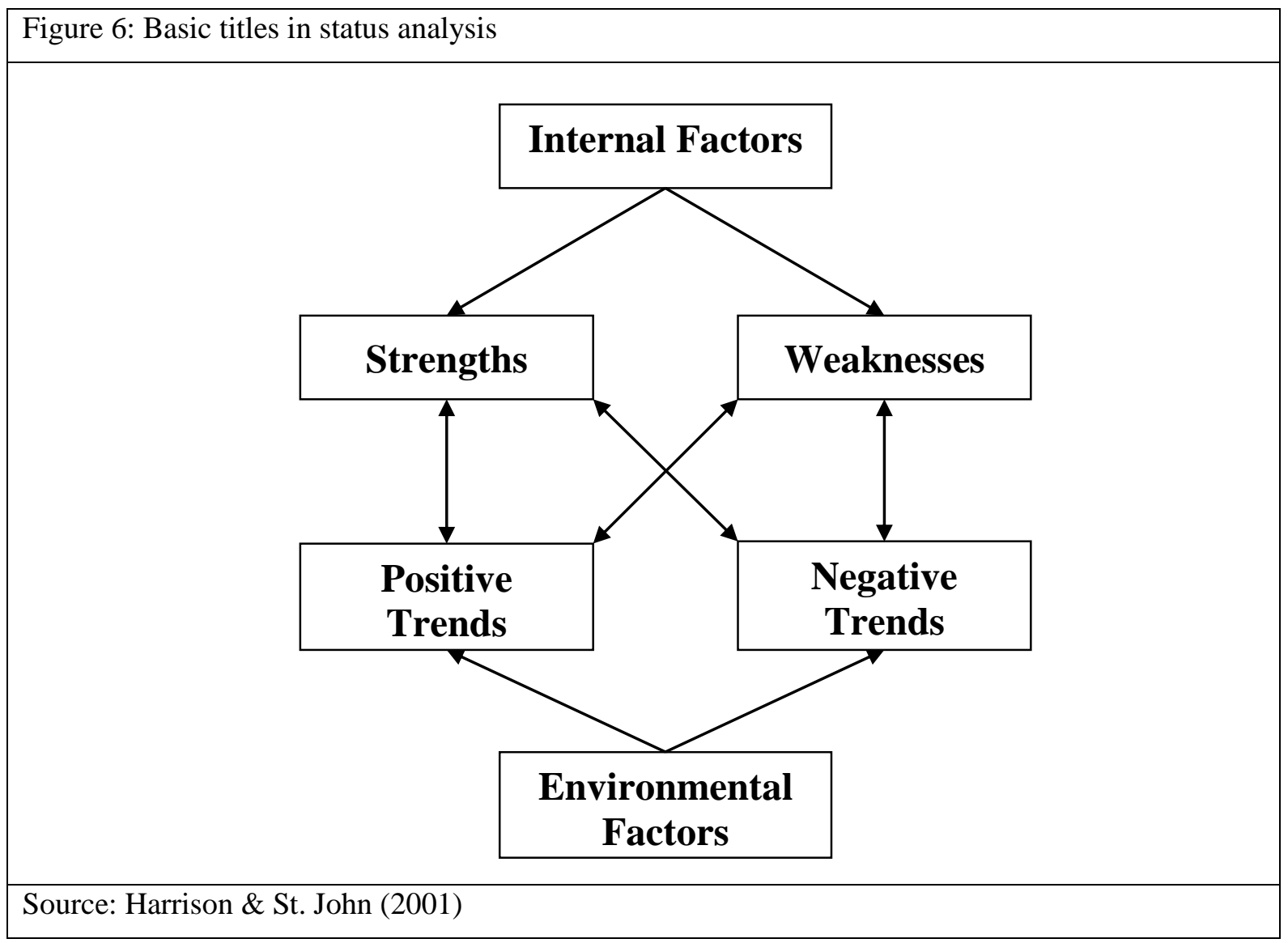

During and after status analysis, the internal strengths and weaknesses of the organization and developments originating from the external factors are identified (see Figure 6).

Status analysis begins with a short history of the business and lays down the policies followed and performance demonstrated by the business during recent years within the framework of its mission. Thus, the conformity of goods and/or services produced by the business to the overall goals and policies, and how the business serves its target group (the general strategies adopted in this respect, etc.) are assessed.

The purpose is to identify the potential of the business taking into consideration its existing performance and problems. The strengths to be identified will shed some light on the future goals of the business, whereas its weaknesses will form the basis of the measures to be taken by the business. Strengths and weaknesses of the business, ascertained within the framework of these studies, are outlined in a summary table.

While making these assessments, the global and domestic trends in the sector or sub-sector, in which the organization operates, are discussed. Intentions of environmental analysis (see Figure 7) are:

- To determine the developments and trends in the macro-economical (demographical, economical, judicial-political, technological, and sociocultural) environment that affects the business and its industry at most.

- To understand the powers that affect competition in the industry (new businesses, customers, suppliers, substitutes, competitors, government, financial institutions, etc.).

- To anticipate the trends that these powers would create for the industry. 
Figure 7: Environmental Analysis

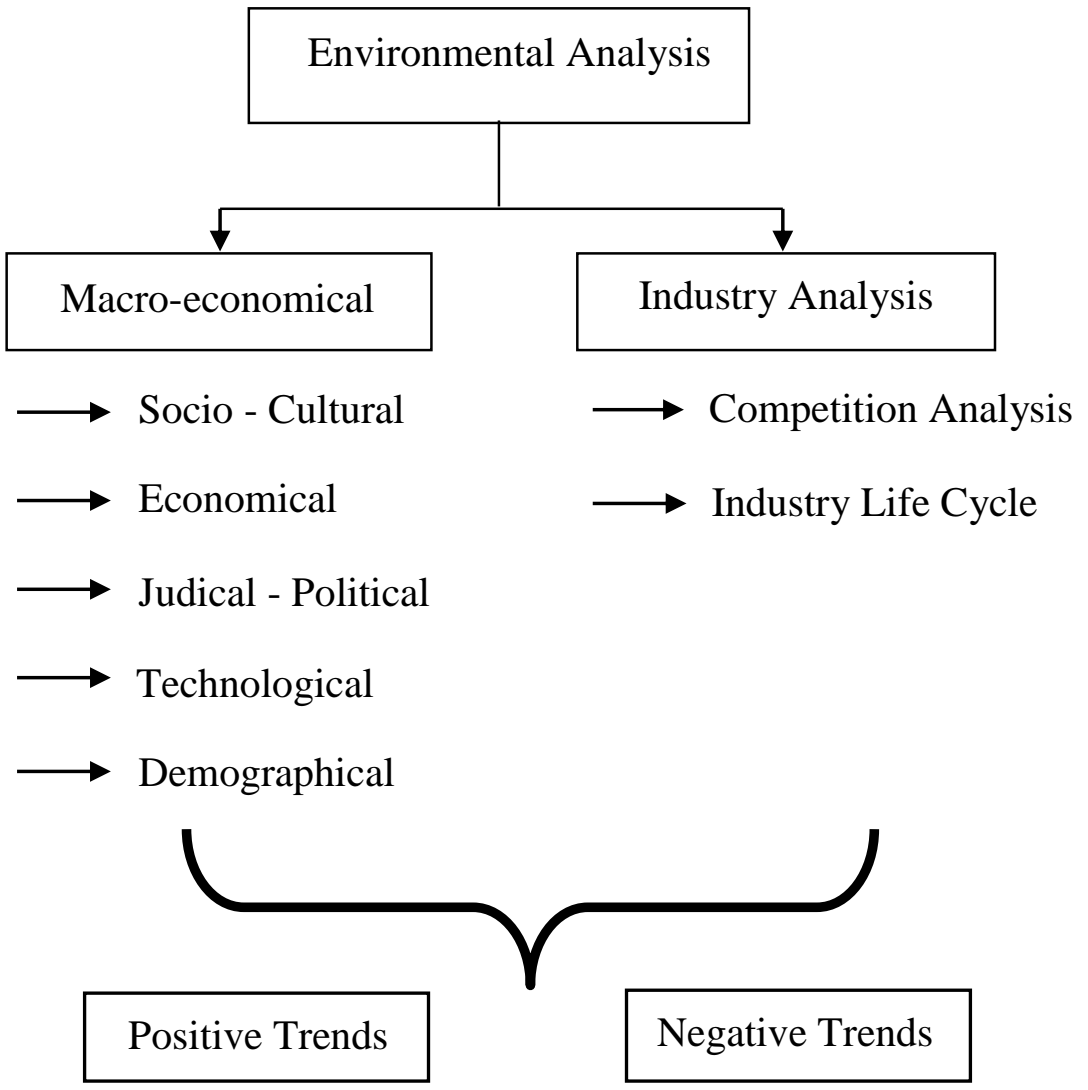

Source: Porter (1998)

\section{Comparison of Status and Identification of Competitive Advantages}

The organization's strengths and weaknesses are compared with the key factors in the market development phases, capacities and resources of main competitors and the industry's success factors, to identify competitive advantages.

A factor is considered a competitive advantage if it is something the business does (or has the future capacity to do) particularly well relative to abilities of existing or potential competitors. Firm gains competitive advantage by performing these strategically important factors more cost effectively or more efficiently than its competitors.

Identifying competitive factors requires an external focus. When key internal factors through analysis of past and present performance are isolated, next step is to identify industry conditions or trends and compare them with the competitors. Changing industry conditions can lead to the need to reexamine internal strengths and weaknesses in light of newly emerging determinants of success in the industry.

The result should be a determination of whether key internal factors (see Figure 8) are:

- Competitive advantages-factors providing the business with an edge against to its competitors, and therefore key factors around, which to build the business strategy.

- Basic business requirements-factors that are important capabilities for the business to have but are also typcial of every viable competitor: does not represent a potential source of any strategic advantage. 
- Key vulnerabilities - factors on which the business currently lacks the necessary skill, knowledge, or resources to compete effectively. This assesment is also a key input because businesses will want to avoid choosing strategies that depend on factors in this category. And businesses usually target key vulnerabilities as areas for special attention so as to remediate and change this situation.

The next step in competitive analysis is to provide the results, or business profile, as input into the systematic strategic planning process. This input is vital during the opportunity determination section.

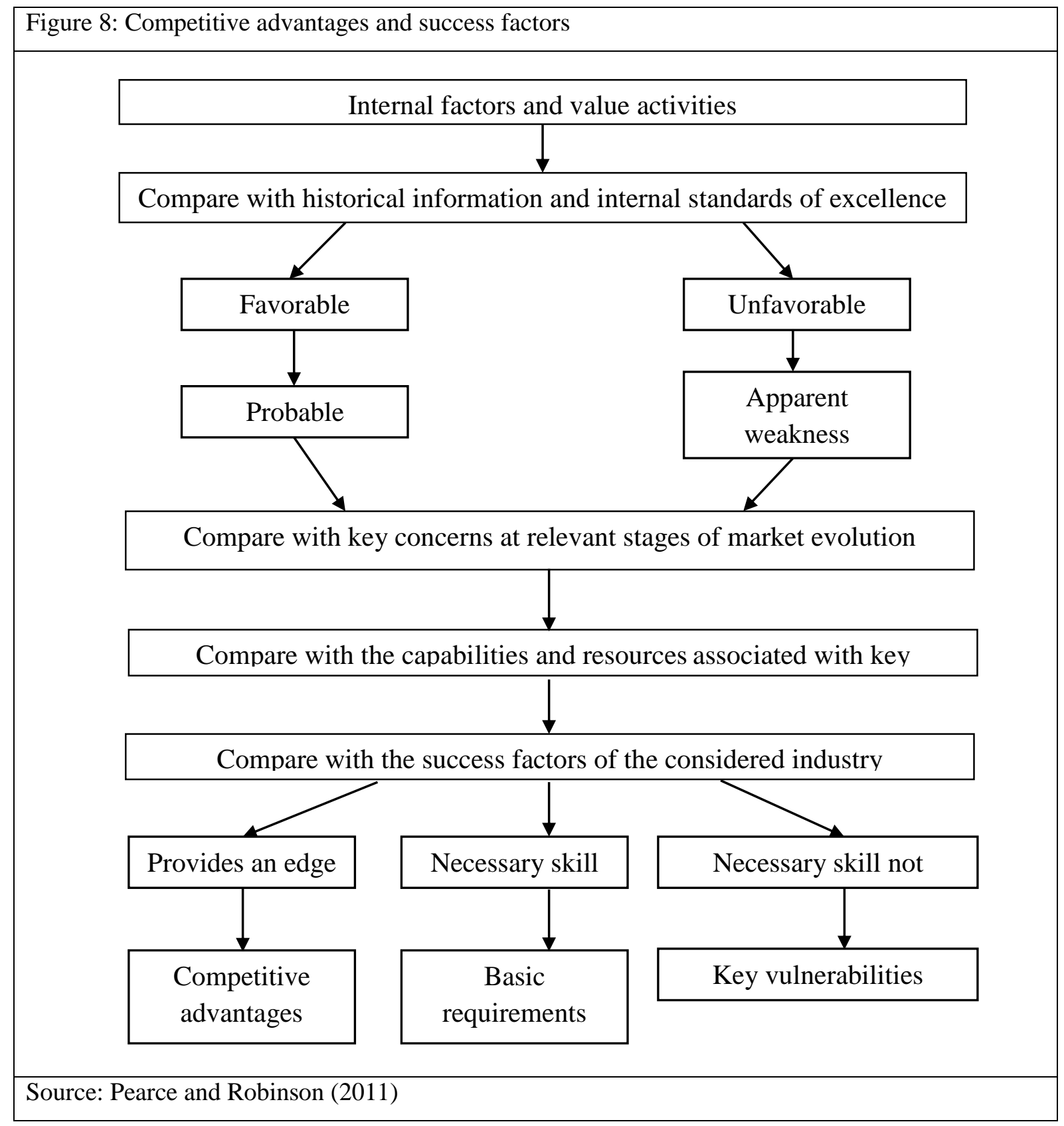

\section{Understanding Scenarios and Defining Opportunities}

Forecasts are made regarding the future changes in the field of business in which the organization operates, or plans to operate in the future (e.g. in what direction will customer needs and expectations evolve and develop in the future). The external variables, which are most sensitive and would affect the results the most if changed, are identified. 
Assumptions are critical in formulating a successful strategy. In other words, the success of strategic plans depends largely on the actualization of assumptions made during the planning process.

Assumptions imply the external factors that are not under the direct control of the business preparing the strategic plan, but that can affect the progress and success of the strategic plan. After reviewing sociocultural factors, technological factors, political environmental, legal conditions, macro-economic factors, and variables originating from international system in the environmental analysis, the tendencies of related parties such as competitors, customers, and suppliers must reflect onto the systematic of strategic planning as assumptions. A schematic diagram illustrating the process of analyzing scenarios and defining opportunities is shown in Figure 9.

Assumptions are made based on these variables, for instance, through brainstorming approach. The status is reviewed according to the assumptions and the results to be obtained are evaluated. It is important that this step is continuously repeated, taking into consideration evolving conditions and innovations. Thus, assumptions are grouped under various scenarios, their potential positive and negative impacts on the industry are identified, and the potential status in the industry is defined.

Scenarios:

- Internally consistent views of the future.

- Focus on discontinuity and change.

- Explore the impact of the change on key players and how they respond to the environment.

Points to consider while developing the scenarios:

- What will be the boundaries of the industry 5 years later? What are the current boundaries and the value-added chains linked to the industry in which you consider joining?

- Which actors may significantly affect the development of scenarios?

- Who, and to what extent, will be affected by the developments in the industry?

- What are the factors giving direction to the future of the industry? What are the critical unknown factors, rather than the factors possible to forecast?

- What is the most important change that will occur in the sector's balance of powers?

- While scenarios are written in detail, they must be freed from internal inconsistencies.

- Detailed scenarios should not describe the situation five years later, but rather tell about the developments that would take us there during those five years.

In order to promote various ideas during this section, seminars, panels or brainstorming meetings must be organized with experts, both within and outside the organization.

In conclusion, taking into consideration the characteristics of the business that offer competitive advantages, the potential opportunities for the business in the industry are identified.

The opportunities and threats that may be offered and posed for the organization by positive and negative scenarios revealed, by scenario analysis, must be identified. Furthermore, identification of the organization's competitive advantages and weaknesses relative to competitors and industry standards could lead this section to an efficient result.

In short, in order to identify opportunities and threats, the organization's competitive advantages and weaknesses must be compared with potential positive (attractive) and negative (risky) scenarios that may be encountered in the industry.

By testing out total market attractiveness of each positive scenario, we would be able to screen out investment opportunities even before considering what kind of competitive strengths might be able to attain. 
Not all opportunities are equally valuable. A business with limited resources cannot pursue every opportunity with which it is faced. It must select those opportunities which are going to be the most rewarding. The key decisions in screening and selecting opportunities relate to the size of the opportunity, the investment necessary to exploit it, the rewards that will be gained and the risks likely to be encountered.

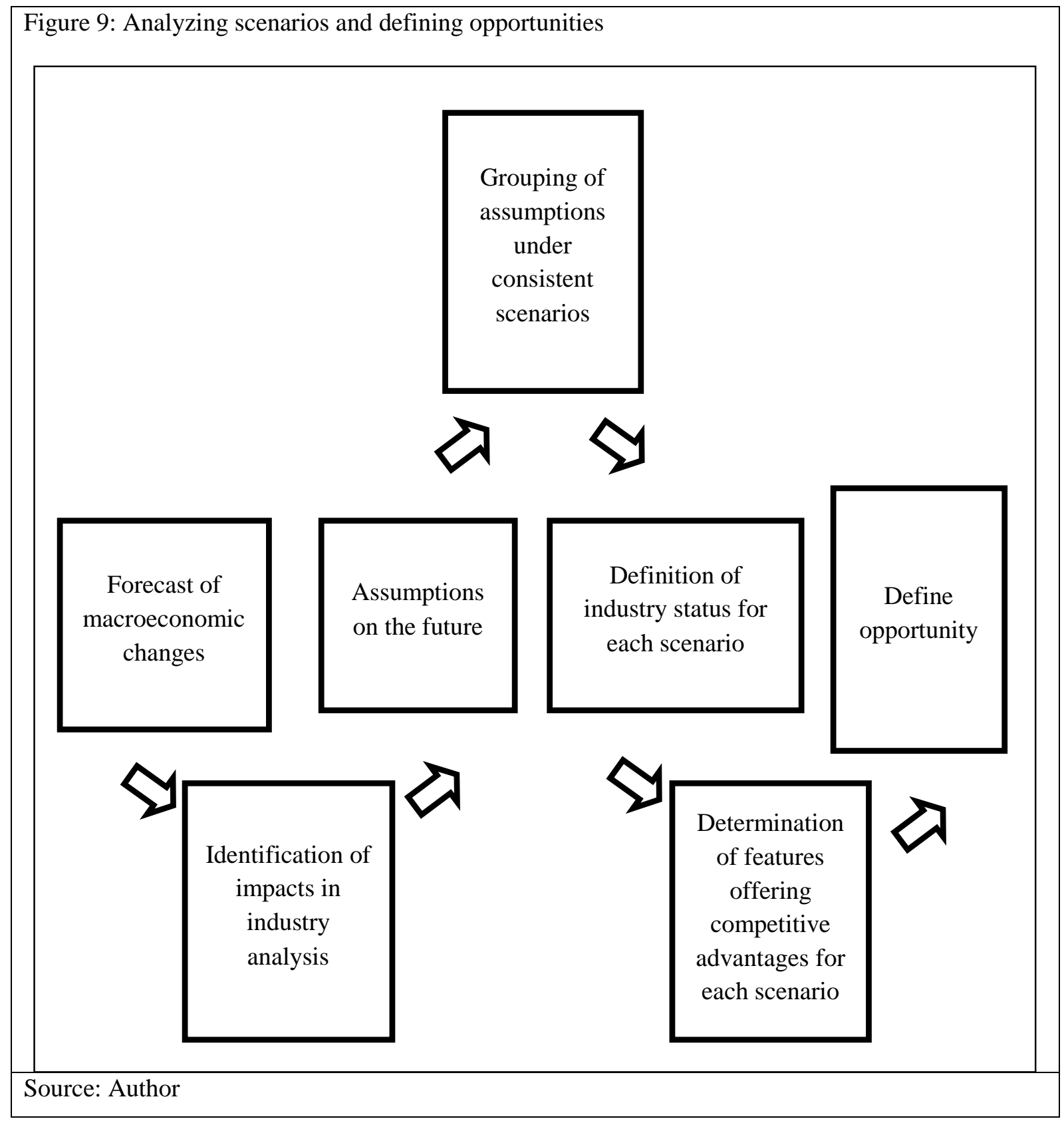

\section{Identification of Strategic Objectives, Main Goals, and Development of Alternative Strategies}

The parameters constituting the assumed opportunities need to be laid down as strategic objectives and main goals. Another important point in this section is to avoid selecting too many goals, which are hard to follow and understand. The things done well and poorly should also be utilized when identifying strategic objectives and main goals.

Furthermore, strategic objectives and main goals should be used for following up the strategies to be developed and the functional plans to be prepared under these strategies. Strategic objectives are the 
conceptual results, which the organization aims at achieving within a certain period of time. Strategic objectives and goals answer the organization's question "what do we want to achieve?"

Main goals are the specific and measurable sub-objectives established for the achievement of strategic objectives. Unlike strategic objectives, goals are expressed quantitatively and cover a shorter term. Multiple goals may be set to achieve a strategic objective.

For example:

- Operational goals

- Marketing goals

- Financial goals

Strategies are instruments ensuring the achievement of long-term goals. It is a course of action selected from a series of options in order to achieve a goal establish against uncertainties.

For the organization to achieve a lasting competitive advantage in its own industry and markets, it searches for answers to the question "what should be done?" and develops alternative strategies. So, it is necessary to analyze what should be done and how should they be done to attain opportunities and thus achieve goals, as well as to identify alternative strategies.

Determination of a suitable strategy for a business begins in identifying the opportunities and risks in its environment. This is concerned with the identification of a range of alternative strategies, the narrowing of this range by recognizing the constraints imposed by business capability, and the determination of one or more strategies at acceptable levels of risk. While evaluating the opportunities defined on the basis of analyses conducted, various strategies we can implement are:

- There should only be one single strategy for a single opportunity.

- If there are multiple opportunities, multiple strategies can be deployed (see Figure 10).

Figure 10: Strategic Guidelines
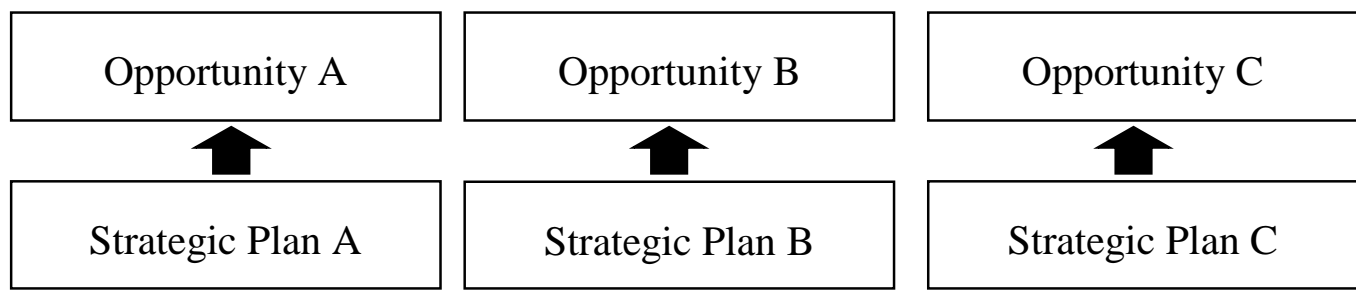

Source: Wright, Parnell, \& Kroll (1997)

Based on the use of both the techniques of generic competitive strategies and components of strategy, the main strategy(ies) can be identified. For example:

- Concentration

- Market development

- Product development

- Innovation

- Horizontal integration

- Vertical integration 


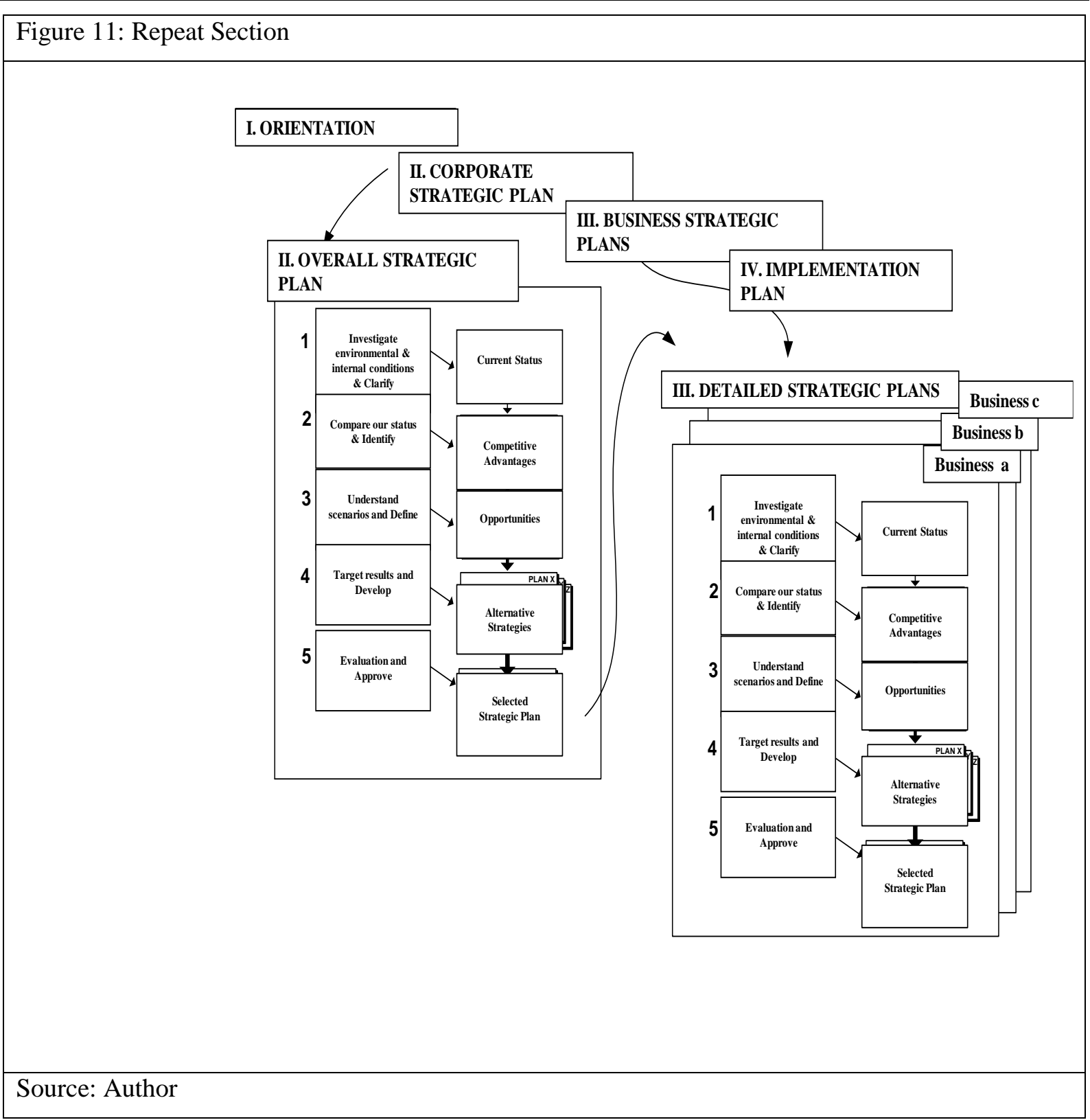

\section{Evaluating Strategic Plans and Selecting the Best}

Here the strategic plan most suitable for the organization is selected. To do this, we make an evaluation of the alternatives based on qualitative factors.

For example:

- Synergy

- Competitive advantages

- Flexible organization structure

- Market orientation

Critical success factors, etc.

Only by making an evaluation as objectively and impartially as possible, we can come up with the best decision. Techniques that may be applied simultaneously or interchangeably to select the best of alternative strategies are:

- Factors analysis 
- Strategic option grid

- Risk drivers

- Financial evaluation

Furthermore, it is necessary to evaluate the profitability of alternative strategy and the risk elements from which it may be affected (mainly labor force, management, client, etc.) and to identify the probability of its actualization within the plan. Hence, alternative strategies should be listed from the least risky to riskiest (considering their probability of actualization.)

Even if the best strategy is selected, by any of these techniques, contingency plans are still necessary for the selected strategy in a risky environment. A sensitivity analysis needs to be conducted, taking into consideration the possibility that basic assumptions and parameters do not come out as expected and the measures considered to be taken in this respect need to be identified.

\section{Repeated Sections}

The sections of full SSP version are repeated in Phases II and III (see Figure 11). The sections are applied once during Phase II, to develop overall strategic plan. Then, the sections are repeated in Phase III for each business or division.

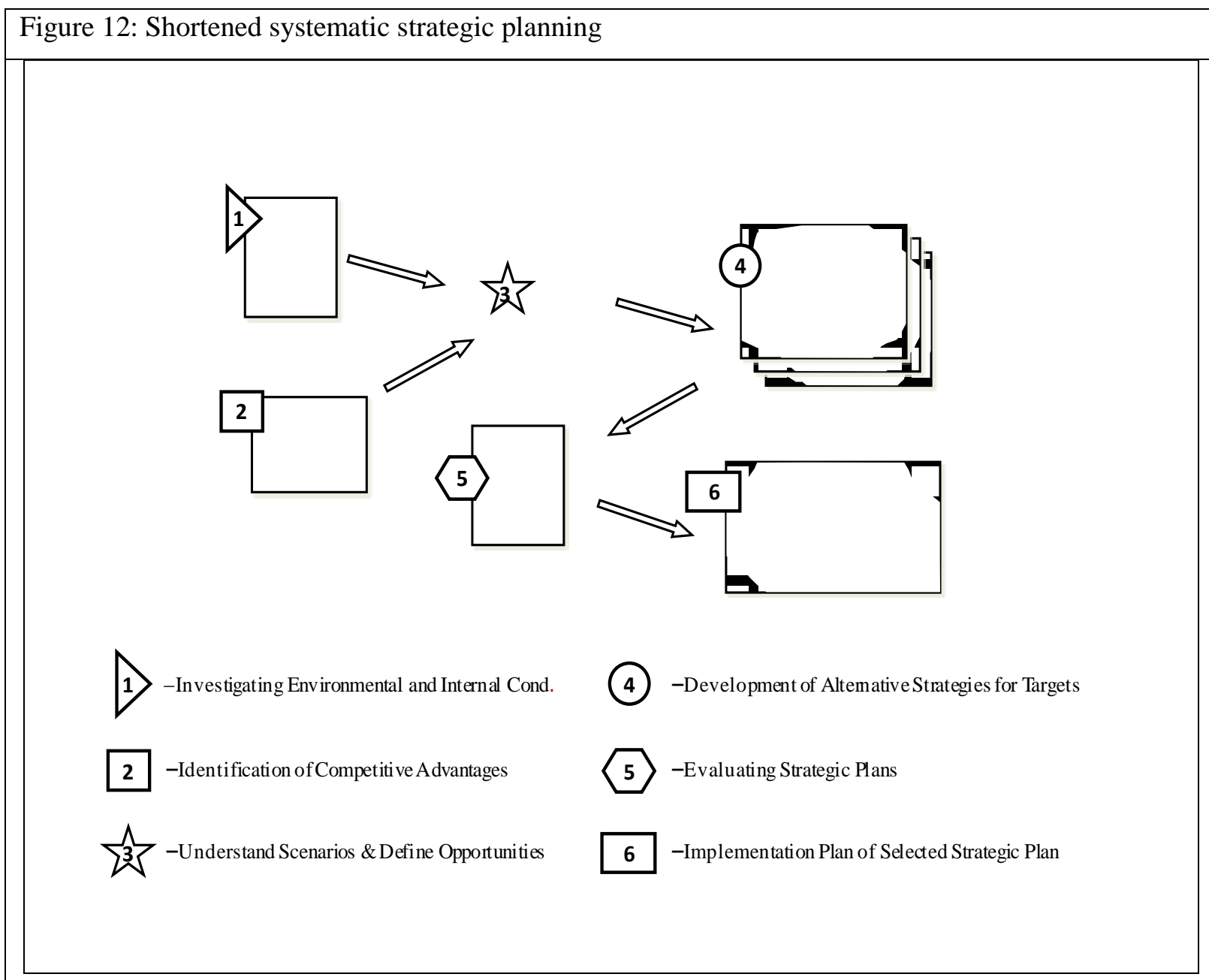

Source: Author 


\section{Systematic Strategic Planning-Shortened Version}

Shortened Systematic Strategic Planning consists of six steps only (see Figure 12). Planning specialist may combine Phases II and III under the Shortened SSP version. Phase IV is defined as Step 6 in the Shortened SSP version.

A strategic plan includes the fundamentals Competitive Advantages, Scenarios, and Strategies. Shortened SSP constitutes a six-step method intended to identify these three fundamentals.

The use of Shortened SSP version is more suitable for the development of strategic plans for small and medium size businesses (SMEs).

\section{Conclusion}

The need for a systematic method of strategic planning is, as many sources exhort managers to 'think strategically' and this is most frequently done conceptually rather than showing how to use the tools for strategic planning. Accordingly, this systematic methodology is brought out in order to assemble the disconnected and disorderly ideas, processes, and techniques (written on strategy and business development) under the same roof, and be easily understood and applied.

The aim of systematic strategic planning (SSP) is to force a look into the future and, therefore, provides an opportunity; to influence the future, or assume a proactive posture; to provide better awareness of needs and environment; to help define and focus on the objectives of the organization; to provide a sense of direction, continuity, and effective leadership; and to plug everyone into the system and provides standards of accountability for people, programs, and allocated resources.

Systematic strategic planning - full version consists of a framework of four phases through which each project passes, a pattern of five sections for straight-forward planning, and the three fundamentals (competitive advantages, scenarios and strategies) involved in any strategic planning project.

Systematic strategic planning - shortened version consists of only six steps. Planning specialist may combine Phases II and III under the shortened SSP version. Phase IV is defined as step 6 in the shortened SSP version. Therefore, shortened SSP constitutes a six-step method intended to identify the three fundamentals. The use of shortened SSP version is more suitable for the development of strategic plans for small and medium-sized enterprises (SMEs).

\section{References}

Abrams, R. M., \& Kleiner, E. (2000). The Successful Business Plan: Secrets and Strategies (3rd ed.). Running R. Media. Bütüner, H. (2004). Stratejik Yönetim: Neden, Nasıl? [Strategic Management: Why, How?] (1st ed.). Rota Yayın. Harrison, J. S., \& St. John, C. H. (2001). Foundations in Strategic Management (2nd ed.). South-Western Publications. Hax, A. C., \& Majluf, N. S. The Strategy Concept and Process: A Pragmatic Approach (2nd ed.). Prentice Hall. Hill, C. W. L., \& Jones, G. R. (2001). Strategic Management: An Integrated Approach (5th ed.). Houghton Mifflin College. Hitt, M. A., Ireland, R. D., \& Hoskisson, R. E. (2005). Strategic Management: Competitiveness and Globalization (6th ed.). South-Western Thomson.

Muther, R. (2011). Planning by Design (1st ed.). Institute for High Performance Planners.

Pearce, J., \& Robinson, R. (2011). Strategic Management: Formulation, Implementation and Control (12th ed.). McGrawHill.

Pietersen, W. (2002). Reinventing Strategy: Using Strategic Learning to Create and Sustain Breakthrough Performance (1st ed.). John Wiley \& Sons.

Porter, M. E. (1998). Competitive Strategy: Techniques for Analyzing Industries and Competitors. The Free Press.

Wheelen, T. L., \& Hunger, J. D. (2001). Strategic Management and Business Policy (8th ed.). Prentice Hall.

Wickham, P. A. (2004). Strategic Entrepreneurship (3rd ed.). Pearson Education Limited.

Wright, P., Parnell, J., \& Kroll, M. (1997). Strategic Management: Concepts (4th ed.). Prentice Hall. 